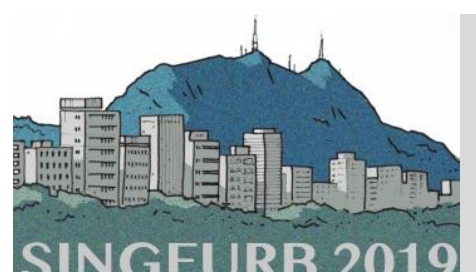

II Simpósio Nacional de Gestão e Engenharia Urbana

ABORDAGEM SISTÊMICA, ESCALAS E INTERSETORIALIDADE: DESAFIOS E POTENCIAIS DO DESENVOLVIMENTO URBANO SUSTENTÁVEL

27 a 29 de novembro - USP

\title{
Implicações dos condomínios habitacionais horizontais fechados à dinâmica das cidades e propostas de mitigação sob a perspectiva da Engenharia Urbana
}

\section{Implications of closed horizontal condominiums to city dynamics and mitigation proposals from the perspective of Urban Engineering}

\author{
Pedro Bon, Frederico'; Fernandes, Ricardo Augusto Souza2; Kowalski, Luiz \\ Fernando3; Olivatto, Tatiane Ferreira4; Masiero, Érico ${ }^{5}$. \\ 1 Universidade Federal de São Carlos - UFSCar. Departamento de Engenharia \\ Civil - Programa de Pós-graduação em Engenharia Urbana. Rodovia \\ Washington Luís, km 235 - SP-310. São Carlos - São Paulo, CEP 13565-905, Brasil. \\ fredericoejr@gmail.com \\ 2 Universidade Federal de São Carlos, ricardo.asf@gmail.com \\ 3 Universidade Federal de São Carlos, fernando.kowalski@ucb.org.br \\ 4 Universidade Federal de São Carlos, tatianeolivatto@yahoo.com.br \\ 5 Universidade Federal de São Carlos, ericomasiero@yahoo.com.br
}

\begin{abstract}
RESUMO
Os condomínios habitacionais horizontais fechados afetam a dinâmica das cidades, pois apresentam-se como obstáculos à mobilidade, à integração e ao uso democrático do espaço público. Assim, este trabalho busca constatar os impactos negativos causados por esses empreendimentos e propor medidas de mitigação, sob a perspectiva da engenharia urbana. Para isso, foi considerada como base uma coletânea de intervenções encontradas na literatura. Na busca por resultados, é proposta uma asserção sintética de intervenção nos muros de um condomínio horizontal habitacional fechado e em sua via de acesso, localizado na cidade brasileira de Engenheiro Coelho/SP. Esta intervenção visou a democratização urbana e a resiliência das comunidades impactadas por esse tipo de empreendimento, além da restituição do direito à cidade e da minimização da segregação socioespacial, garantindo acesso às áreas públicas, acessibilidade e consonância com as políticas de mobilidade urbana.
\end{abstract}

Palavras-chave: Condomínios habitacionais horizontais fechados, Planejamento urbano, Engenharia urbana.

\section{ABSTRACT}

Closed horizontal condominiums are affected by the dynamics of the cities. It is an obstacle

PEDRO BON, Frederico 1; FERNANDES, Ricardo Augusto Souza 2; KOWALSKI, Luiz Fernando 3; OLIVATTO, Tatiane Ferreira 4; MASIERO, Érico 5. Implicações dos Condomínios Habitacionais Horizontais Fechados à Dinâmica das Cidades e Propostas de Mitigação sob a Perspectiva da Engenharia Urbana. In: II SIMPÓSIO NACIONAL DE GESTÃO E ENGENHARIA URBANA: SINGEURB, 2019, São Paulo. Anais... Porto Alegre: ANTAC, 2019. 
to the mobility, integration and democratic use of public space. Thus, this paper aims to determine the negative impacts in relation to closed horizontal condominiums and based on examples found in the literature review. Then, an intervention in the walls and access road at a closed horizontal condominium stated on the Brazilian city of proposed mitigation strategies from an urban engineering perspective. For that, a study in the city of Engenheiro Coelho/SP was proposed. This intervention aims the democratization and resilience of communities impacted by this type of real estate enterprise, as well as the restitution of the right to citizenship and the minimization of socio-spatial segregation, guaranteeing access to public areas, accessibility and a consonance with urban mobility policies.

Keywords: Closed horizontal condominiums, Urban planning, Urban engineering.

\section{INTRODUÇÃO}

No Brasil, a partir de 1956, concomitantemente ao processo de industrialização, o processo de urbanização tornou-se cada vez mais acelerado. De acordo com o Instituto Brasileiro de Geografia e Estatística (IBGE, 2010), em 1940, 30\% da população brasileira morava em zonas urbanas. Em 1970, esse número já ultrapassava 50\%. De acordo com o Censo de 2010, mais de $80 \%$ da população brasileira já é urbana.

O surgimento dos assentamentos urbanos é considerado um resultado de fatores históricos, geográficos e, acima de tudo, sociais. A partir da segunda etapa da revolução industrial entre 1850 e 1860, emerge o termo urbanismo, empregado pela primeira vez por lldefonso Cerdá em 1859 no sentido de planejamento urbano (ALEXANDRA; NARCISO, 2013).

A partir de então, uma tendência de modificação do espaço urbano encontra-se na proliferação de núcleos habitacionais fechados. Apesar da evidência destes impactos, a literatura sobre o assunto é escassa, sendo mais escassas ainda publicações sobre possíveis medidas mitigadoras. No continente americano, na Austrália e no Sul da África prevalecem as publicações com foco em segurança e desigualdade social justificando a busca pelos condomínios (Cruz e Pinho, 2009).

Com base no exposto, este trabalho pretende levantar as principais implicações correlatas aos condomínios habitacionais horizontais fechados (CHHF) no espaço urbano, à luz de casos encontrados na literatura, bem como propor estratégias para mitigação das implicações encontradas em um caso estudado na cidade brasileira de Engenheiro Coelho/SP.

\section{METODOLOGIA}

Este estudo consiste em uma investigação de materiais bibliográficos, baseado no método materialista-histórico. O procedimento fundamenta-se primariamente na exploração da literatura científica com o intuito de identificar os principais impactos da instalação dos condomínios habitacionais horizontais fechados a partir de casos que generalizam a problemática. Na sequência, ocorre a caracterização do município de Engenheiro Coelho/SP - Brasil, como ambiente de estudo para correlação dos problemas previamente encontrados. Por fim, é feita uma proposta simplificada de intervenção no CHHF Lagoa Bonita, já consolidado, a partir das premissas da engenharia urbana.

\section{IMPACTOS DOS NÚCLEOS HABITACIONAIS FECHADOS}

\subsection{Impactos à dinâmica das cidades}

Cruz e Pinho (2009) notaram que em alguns países como Estados Unidos, Brasil, México e África do Sul, os CHHF se apresentam em larga escala e se desenvolvem de forma autossuficiente, destacados do contexto da cidade em que estão inseridos.

De forma geral, segregação, exclusividade e espaços fragmentados são as palavras de ordem para a produção desses espaços. Cruz e Pinho (2009) perceberam, como produto da segregação física, a ausência do senso de comunidade como grande causa dos problemas. 
Os indivíduos buscam por comunidades que os enclaves são particulares de um determinado estilo de vida.

Os espaços públicos perderam seu caráter de sociabilidade e de promoção do coletivo enfraquecendo assim as conexões sociais e os valores comunitários.

\subsection{Impactos sociais}

Villaça (2011) afirma que a forma mais destacada de estudo da segregação moderna é sua manifestação sob a forma dos CHHF, pois ainda não há a preocupação em colocar a segregação como um dos fatores da estrutura urbana juntamente com as esferas da economia, política e ideológicas da sociedade. Além disso, há uma articulação eminente em aliar os interesses imobiliários, à segurança, violência urbana e a uma nova cultura criada.

A questão da segregação está aquém das boas relações sociais. "A segregação é um processo segundo o qual diferentes classes ou camadas sociais tendem a se concentrar cada vez mais em diferentes regiões gerais ou conjuntos de bairros da metrópole" (VILLAÇA, 2001, p. 142).

\subsection{Impactos no direito e acesso à cidade}

Melgaço (2012) apresenta uma visão dos CHHF sob a perspectiva da estética dos muros de uma prisão. O autor enfatiza que "as formas são praticamente as mesmas e as funções têm apenas uma diferença de direção: enquanto no primeiro caso a arquitetura visa impedir a entrada de quem está do lado de fora, no segundo, pretende impedir a saída dos que estão do lado de dentro". A partir desta comparação, o autor pretende realçar a semelhança entre as estruturas e provocar uma reflexão sobre a transformação dos espaços urbanos e suas consequências na arquitetura das cidades.

Visando viabilizar a implantação deste tipo de empreendimento, este modelo de urbanismo está se tornando comum em grande parte dos municípios brasileiros. Seco (2017) aponta a ausência de vitalidade nas ruas ao redor dos núcleos fechados como principal causa de insegurança na vizinhança. O autor afirma que a "movimentação de carros e gente promove - contato visual das casas, edifícios e comércios com o espaço público, estimulando a circulação de pessoas durante vários horários do dia e criando o que alguns especialistas chamam de vigilância natural".

\subsection{Impactos à mobilidade urbana}

Percebe-se uma mudança no traçado urbano com o surgimento desses empreendimentos. Sarmento Filho (2012) ressalta que, no Brasil, a implantação dos CHHF provoca um verdadeiro caos nas cidades, pois na maioria dos casos o requisito para a aprovação junto aos órgãos públicos municipais é que o projeto das ruas esteja integrado ao sistema viário principal, o que não é nada representativo para um traçado urbano sustentável.

Além disso, tendo em vista as diretrizes do Plano Nacional de Mobilidade Urbana, torna-se evidente que os impactos desses empreendimentos causam uma quebra no desenho da cidade, formando ilhas que impedem o fluxo de transporte e movimentação intraurbana, forçando desvios que aumentam o tempo no trânsito, além de incentivar o uso de transporte individual motorizado (ROSA, 2016).

Melgaço (2012) aponta o surgimento de bloqueios de vias públicas. Assim, os obstáculos à circulação de veículos ocasionam a sobrecarga das vias de circulação adjacentes, bem como aumentam as distâncias para ciclistas e pedestres.

\subsection{Privatização das áreas públicas}

Apesar do surgimento da Lei Federal 13.465/2017, que introduz a possibilidade de loteamentos de acesso controlado, o artigo 17 da Lei Federal 6.766/1979 (revisada pela Lei 9.785/1999) 
esclarece que "espaços livres de uso comum, as vias e praças, [...] não poderão ter sua destinação alterada pelo loteador".

Na prática, como foi identificado pelo estudo desenvolvido por Cruz e Pinho (2009), se observa uma busca por status social através da exclusividade expressa mediante serviços e facilidades oferecidos intramuros, pelas administradoras, para promover a sociabilidade apenas entre os residentes como playground, piscinas, quadra de tênis e até mesmo espaços de cuidados com a saúde e academias. Observou-se uma tendência de gerenciamento dos equipamentos públicos pelas administradoras dos $\mathrm{CHHF}$, intensificando ainda mais $\mathrm{O}$ distanciamento entre os não moradores dos CHHF e as áreas ditas públicas.

\section{ESTUDO DE CASO: ENGENHEIRO COELHO/SP - BRASIL}

\subsection{Caracterização geográfica e legal da área de estudo}

Criado em 1991, Engenheiro Coelho é um município paulista localizado a nordeste do Estado de São Paulo, integrando a Região Metropolitana de Campinas (RMC). Possui uma área total de 109,94 km² (SEADE, 2018) e 19.628 habitantes (SEADE, 2018), sendo um dos municípios com menor população da RMC. É também o município menos urbanizado, com uma taxa de urbanização de 75,58\% (SEADE, 2018).

A região de estudo é composta por loteamentos abertos e CHHF, os quais acompanharam o crescimento de um campus universitário da UNASP implantado na década de 80 . Conforme Figura 1, a área de estudo é compreendida por dois CHHF: Lagoa Bonita III e Portal do Lago (demarcados em amarelo) e a Estrada Municipal Pr. Walter Boger (demarcada em vermelho), que provê acesso aos condomínios e a UNASP (demarcada em verde).

Figura 1- Localização do objeto de estudo

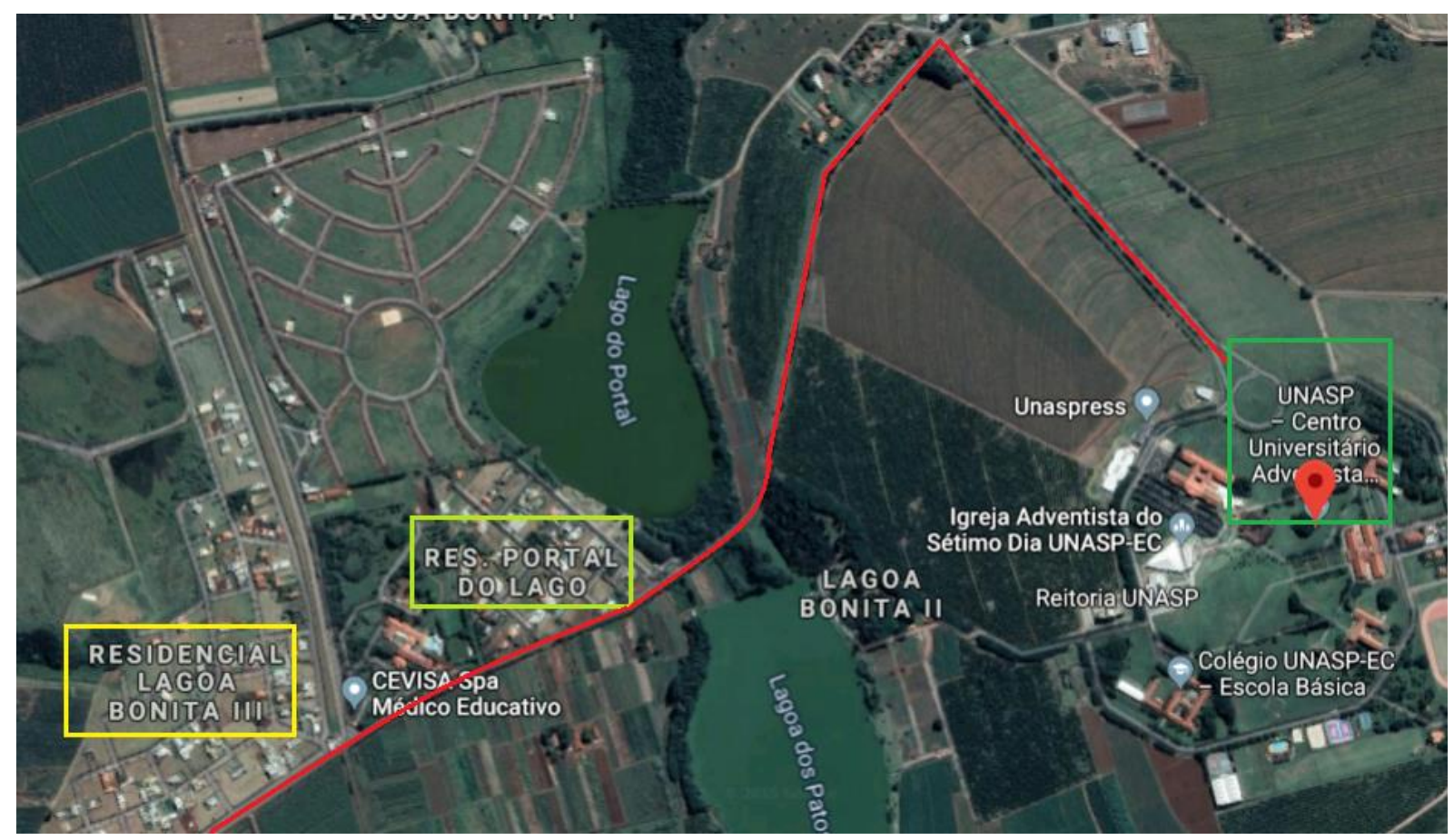

Fonte: Adaptado de Google Earth (2018)

\subsection{Diagnóstico dos problemas relacionados ao CHHF Lagoa Bonita}

A configuração atual do CHHF com fechamento murado em todo o seu perímetro incorre em alguns problemas aos estudantes do centro universitário, aos motoristas e ciclistas e a população em geral que utiliza a Estrada Municipal Pr. Walter Boger, conforme: 
- Os muros apresentam-se como obstáculos à mobilidade urbana;

- Extensões muradas incorrem em distâncias maiores a serem superadas principalmente pelos pedestres;

- Os muros explicitam segregação, perda de direito à cidade por parte daqueles que não habitam no CHHF e promovem dissolução da coesão social;

- As ruas internas não dão continuidade às ruas externas, eliminando possibilidade de integração do empreendimento à dinâmica da área;

- O acesso de veículos da via para o condomínio é feito de forma direta e cruzando a faixa de rolamento oposta.

Neste cenário, uma intervenção drástica e eficaz, extinguiria a portaria bem como possibilitaria a reintegração das vias internas ao uso livre público. Contudo, este tipo de intervenção foi inviabilizado por dois motivos:

- As vias internas não dão continuidade ao sistema viário externo, em outras palavras, mesmo que reintegradas ao uso público geral, as vias internas não teriam de fato serventia pública;

- Contrariedade as premissas da Lei Federal 13.465 de 2017, que prevê a regularização fundiária urbana.

\subsection{Proposta de intervenção mitigadora, resultados e discussões}

Face ao exposto na seção anterior e considerando a coletânea de intervenções encontradas na literatura, foram elaboradas duas intervenções menos intransigentes: (i) a transformação do muro de fechamento do CHHF em cerca e consequente (ii) deslocamento a fim de externalizar parte das áreas verdes que são paralelas ao muro e internas ao CHHF, conforme a Figura 2 e Figura 3.

Figura 2 - Composição atual

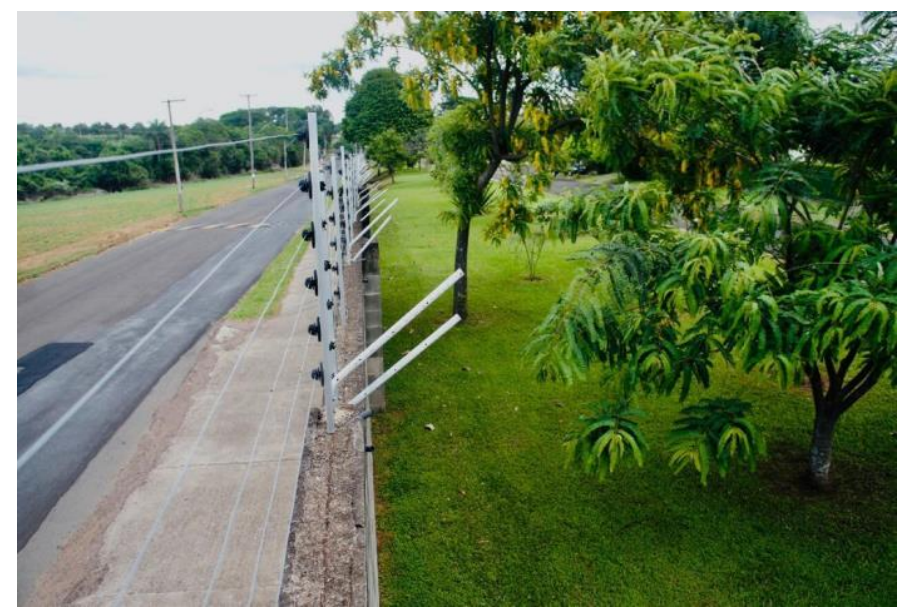

Fonte: Os autores (2018) 


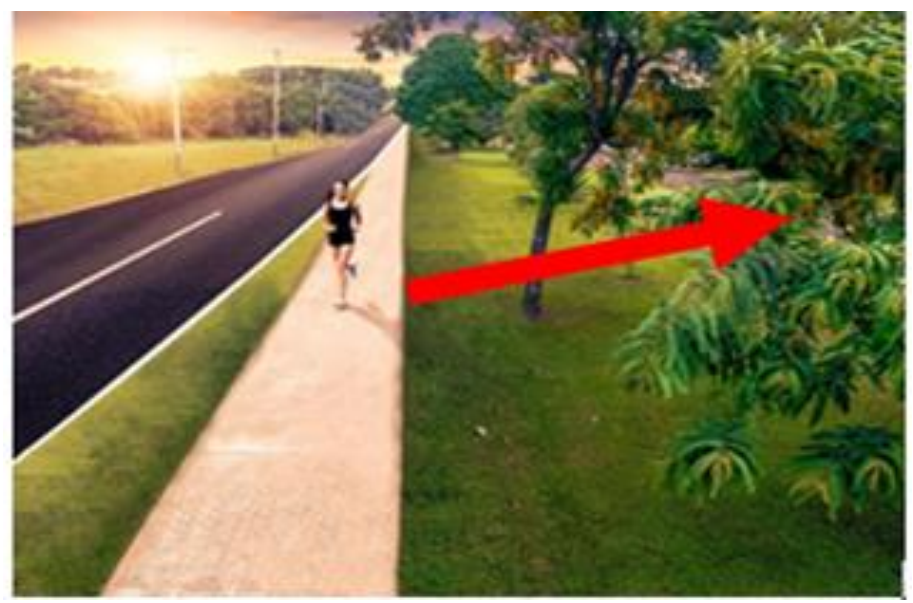

Fonte: Os autores (2018)

A transformação do muro em cerca mantém a sensação de segurança aos internos, contudo, amenizando a barreira física de segregação social ao proporcionar permeabilidade visual. Já a externalização de parte das áreas verdes, permitiria a utilização pública do espaço. Assim, a área externalizada acaba por viabilizar a implantação de um parque linear que criaria de fato uma área de interesse ambiental. A Figura 4 ilustra a situação pretendida com estas alterações.

Atualmente, as áreas verdes localizadas internamente ao fechamento possuem apenas função paisagística (jardim). A partir do deslocamento e da implantação do parque linear, as áreas públicas de interesse ambiental passam a ser utilizadas pela população além dos muros do empreendimento com intuito de amenizar os impactos negativos resultantes de sua consolidação.

Figura 4 - Localização das áreas verdes pretendidas

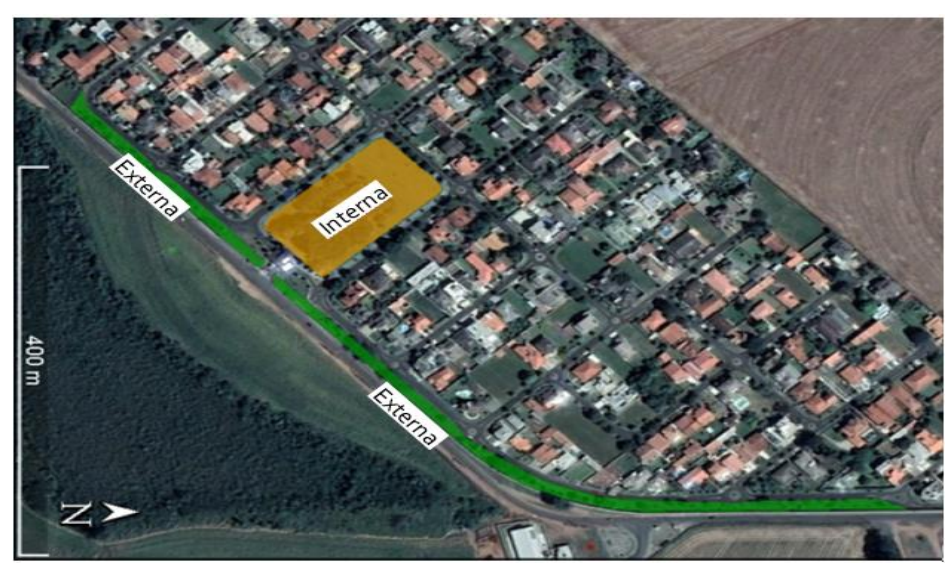

Fonte: Adaptado do Google Earth (2018)

\section{CONCLUSÕES}

Os CHHF na dinâmica das cidades, incluindo o caso de aplicação analisado, apresentam-se como obstáculos à mobilidade, a integração e ao uso do espaço público.

Sendo assim, as intervenções à área de estudo se resumiram à substituição dos muros por cercas de gradeamento que conferem permeabilidade visual. Esta intervenção visa dinamizar os espaços e passeios públicos e promover vigilância natural. Essa alteração, associada à criação do parque linear a partir da externalização de parte dos espaços públicos e adaptações da via de acesso ao empreendimento aferem uma condição mais 
agradável e segura aos moradores e não moradores do CHHF, além de garantir a acessibilidade em conformidade com a Política Nacional de Mobilidade Urbana (PNMU), Lei Federal 12.587/2012.

Por fim, os impactos negativos identificados e as medidas mitigadoras estudadas não tentam resolver o complexo problema em sua totalidade, mas implementar a democratização urbana a partir da melhoria da mobilidade e integração dos espaços públicos à dinâmica interna dos moradores, da congregação e coesão social com consequente exploração do potencial direito à cidade.

\section{AGRADECIMENTOS}

O presente trabalho foi realizado com apoio da Coordenação de Aperfeiçoamento de Pessoal de Nível Superior - Brasil (CAPES) - Código de Financiamento 001.

\section{REFERÊNCIAS}

ALEXANDRA, C.; NARCISO, F.. Espaço Público: Desenho, Organização e Poder. Riga: Novas Edições Acadêmicas, 2013. 196 p.

Brasil. (1979). Lei $n^{\circ}$ 6766, de 19 de dezembro de 1979. Dispõe sobre o Parcelamento do Solo Urbano e dá outras Providências. Brasília, DF. Disponível em:

<http://www.planalto.gov.br/ccivil_03/LEIS/L6766.htm>. Acesso em: 20 nov. 2018.

Brasil (1999). Lei $n^{\circ}$ 9785, de 21 de janeiro de 1999. Altera o Decreto-Lei $n^{\circ} 3365$, de 21 d ejunho de 1940 (desapropriação por utilidade pública) e as Leis $n^{\circ} 6015$, de 31 de dezembro de 1973 (registros públicos) e 6766, de 19 de dezembro de 1979 (parcelamento do solo urbano). Brasília, DF. Disponível em: <http://www.planalto.gov.br/ccivil_03/LEIS/L9785.htm>. Acesso em: 25 jul. 2019.

Brasil. (2017). Lei $\mathbf{n}^{\circ}$ 12587, de 03 de janeiro de 2012. Brasília, DF. Disponível em: <http://www. planalto.gov.br/ccivil_03/_Ato201 1-2014/2012/Lei/L12587.htm>. Acesso em: 20 nov. 2018.

Brasil. (2017). Lei $\mathrm{n}^{\circ}$ 13465, de 11 de julho de 2017. Brasília, DF. Disponível em: <http://www. planalto.gov.br/ccivil_03/_Ato2015-2018/2017/Lei/L13465.htm>. Acesso em: 20 nov. 2018.

CRUZ, S. S.; PINHO, P. Closed Condominiums as Urban Fragments of the Contemporary City. European Planning Studies, [s.I.], v. 17, n. 11, p.1685-1710, nov. 2009. Informa UK Limited.

IBGE. (2010). Censo Demográfico. População nos Censos Demográficos, segundo as Grandes Regiões, as Unidades da Federação e a situação do domicílio. IBGE, 2010. Disponível em: <https://censo2010.ibge.gov.br/sinopse/index.php? dados=8>. Acesso em: 25 set. 2018.

Melgaço, L. (2012). A cidade de poucos: condomínios fechados e a privatização do espaço público em Campinas. Boletim Campineiro de Geografia,v. 2, n. 1, p.p. 81-105.

Rosa, V. (2016). A ilegalidade dos "condomínios fechados": uma afronta ao desenho da cidade e a mobilidade urbana. In: 4 Colóquio Brasil-Portugal: Estratégias de Projeto e Intervenção nas Metrópoles Contemporâneas: Experiências e Perspectiva. São Paulo: Mackenzie, Nov. 2016.

Sarmento Filho, E. S. C. (2012). Loteamento fechado ou condomínio de fato. Curitiba: Juruá.

SEADE. S.T. Disponível em: http://www.seade.gov.br/. Acesso em 12 abr. 2018.

Villaça, F. (2001). Espaço intra-urbano no Brasil. São Paulo: Studio Nobel. 
Seco, M. (2017). Condomínios fechados podem aumentar a insegurança das ruas ao redor. Metrópolis. 2017. Disponível em:<https://www.metropoles.com/ponto-de-vista/condominiosfechados-aumentam-a-violencia-nao-protegem-familias>. Acesso em: 9 dez. 2018.

VILLAÇA, F.. São Paulo: segregação urbana e desigualdade. Estudos Avançados, [s.l.], v. 25, n. 71, p.37-58, abr. 2011 . FapUNIFESP (SCiELO). 